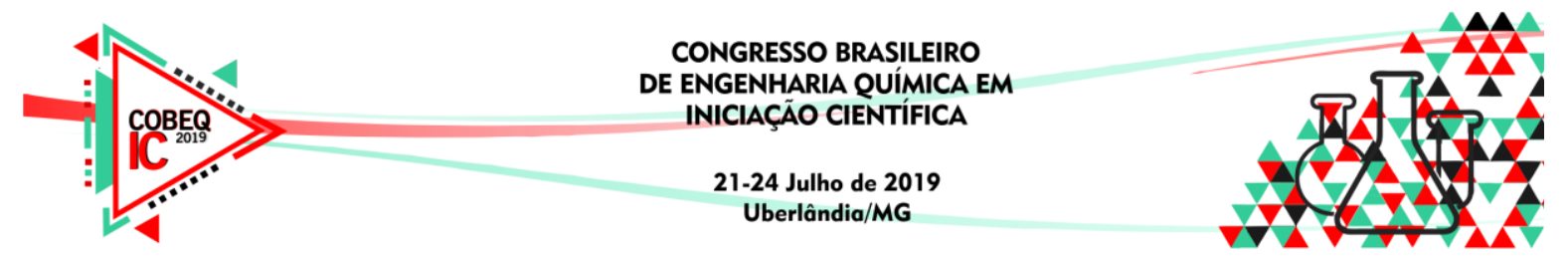

\title{
INFLUENCIA DAS CONDIÇÕES DE CULTIVO NA PRODUÇÃO DE LIPASE LIGADA AO MICÉLIO POR CÉLULAS ÍNTEGRAS DE Aspergillus oryzae
}

\author{
P. M. SATO ${ }^{1}$, F. H. M. SOUZA ${ }^{1}$, G. E. SANTOS $^{1}$ e G. S. S. ANDRADE ${ }^{1}$ \\ ${ }^{1}$ Universidade Federal de Alfenas, Instituto de Ciência e Tecnologia \\ E-mail para contato: grazielle.andrade@unifal-mg.edu.br
}

\begin{abstract}
RESUMO - O presente trabalho teve como objetivo avaliar a influência dos parâmetros nutricionais fontes de carbono e nitrogênio, bem como o pH na produção de lipase ligada ao micélio por células íntegras de Aspergillus oryzae. As células foram cultivadas em fermentação submersa a $30^{\circ} \mathrm{C}$ sob agitação orbital de $170 \mathrm{rpm}$. A curva de crescimento das células revelou um crescimento típico microbiano em que constatou-se que não há uma relação direta e proporcional entre a formação de biomassa e a produção da lipase ligada ao micélio. As condições que favoreceram a produção de lipase ligada ao micélio foram em pH 8 e com adição de óleo de oliva e mistura 1:1 de peptona de soja e extrato de levedura como fontes de carbono e nitrogênio, respectivamente.
\end{abstract}

\section{INTRODUÇÃO}

Lipases ligadas ao micélio vêm sendo cada vez mais estudadas visando identificar o potencial de micro-organismos como bactérias, leveduras e fungos filamentosos, para utilização como biocatalisador (células íntegras) baseado na sua habilidade de imobilização e de exposição das proteínas funcionais de interesse na superfície de sua célula (Cortez et al., 2017).

Como biocatalisadores, as lipases apresentam características como especificidade, regiosseletividade e enantiosseletividade, que os catalisadores químicos não possuem, além de permitirem a síntese de compostos de alta pureza, com um número reduzido de subprodutos e baixa geração de resíduos (Colla et al., 2016). Lipases fúngicas ligadas ao micélio tem tido destaque, em especial quando provenientes de fungos dos gêneros Mucor, Penicillium $e$ Rhizopus, que são citados como bons produtores de lipases (Iftikhar et al., 2008). Entretanto, ainda são poucas as espécies estudadas e por isso, pouco utilizadas industrialmente.

Nesse contexto, o presente trabalho tem como objetivo investigar as melhores condições de cultivo para a produção de lipase ligada ao micélio a partir de células íntegras de Aspergillus oryzae. Espera-se produzir um biocatalisador eficiente e de baixo custo que possa ser utilizado em reações de interesse industrial, tais como hidrólise e transesterificação.

\section{MATERIAIS E MÉTODOS}

\subsection{Materiais}




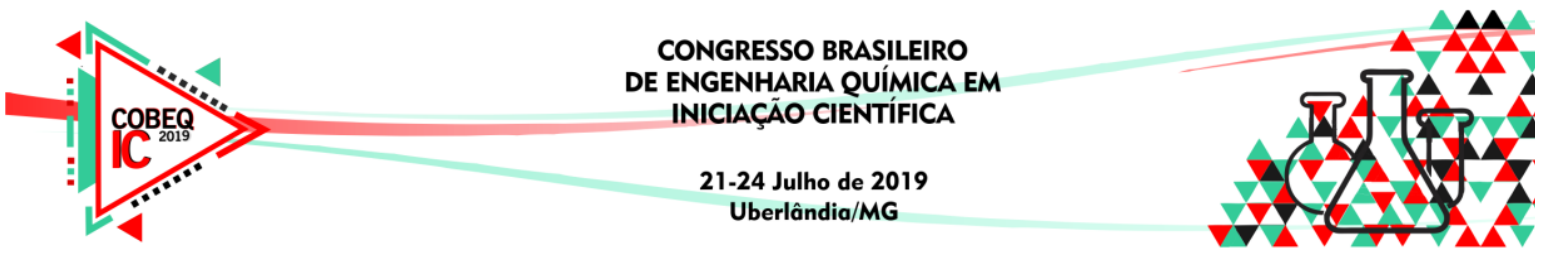

O micro-organismo utilizado no desenvolvimento do trabalho foi o Aspergillus oryzae URM 5618 (Micoteca UFPE). Para o preparo do meio de cultura utilizou-se como fontes de carbono os óleos refinados de canola (Liza), girassol (Liza), soja (Liza) e oliva (Carbonell); como fonte de nitrogênio peptona de soja (Acumedia), extrato de levedura (Acumedia), resíduo de soja okara (produção caseira de tofu), $\mathrm{NH}_{4} \mathrm{Cl}$ (Synth) e $\mathrm{NH}_{4} \mathrm{SO}_{4}$ (Synth); e os sais $\mathrm{NaNO}_{3}$ (Synth), $\mathrm{KH}_{2} \mathrm{PO}_{4}$ (Synth) e $\mathrm{MgSO}_{4} .7 \mathrm{H}_{2} \mathrm{O}$ (Synth). Os outros reagentes utilizados foram de grau analítico: goma arábica em pó pura (Synth) e acetona (Synth).

\subsection{Preparo das células íntegras}

As células íntegras foram preparadas conforme Andrade et al. (2012). Em Erlenmeyers de $250 \mathrm{~mL}$ contendo $100 \mathrm{~mL}$ de meio previamente autoclavado $\left(121^{\circ} \mathrm{C} / 15 \mathrm{~min}\right)$ foram adicionados assepticamente $3 \mathrm{~g}$ de óleo refinado como agente indutor da produção de lipase. Para preparo do inóculo, os esporos foram raspados, suspensos em água estéril e submetidos à agitação até a obtenção de uma suspensão. Um volume de $200 \mu \mathrm{L}$ da suspensão foi inoculado em cada frasco agitado, os quais foram incubados por $96 \mathrm{~h}$ a $30^{\circ} \mathrm{C}$ sob agitação orbital em shaker $(170 \mathrm{rpm})$. Ao final do cultivo, as células foram separadas do meio de cultura por filtração a vácuo, lavadas com água e acetona e secas em bomba de alto vácuo. A biomassa celular foi avaliada por meio de medida de peso seco e a atividade lipolítica foi quantificada pelo método da hidrólise do azeite de oliva modificado (Andrade et al., 2014).

\subsection{Influência dos parâmetros de cultivo}

A fim de aumentar a produção de lipase ligada ao micélio nas células íntegras de $A$. oryzae, foram investigados a influência da fonte de carbono e nitrogênio e do pH. Foram avaliados como fonte de carbono os óleos de oliva, soja, canola e girassol na concentração de $30 \mathrm{~g} \mathrm{~L}^{-1}$; como fonte de nitrogênio investigou-se peptona de soja e extrato de levedura 1:1 (70 $\left.\mathrm{g} \mathrm{L}^{-1}\right)$, peptona de soja $\left(35,50\right.$ e $\left.70 \mathrm{~g} \mathrm{~L}^{-1}\right)$ e okara $\left(35,50\right.$ e $\left.70 \mathrm{~g} \mathrm{~L}^{-1}\right)$; e o $\mathrm{pH}$ do meio de cultura foi testado na faixa entre 5,0 a 8,0 com um incremento de 0,5, através da adição de $\mathrm{HCl}$ ou $\mathrm{NaOH}$ concentrados.

\subsection{Determinação da atividade hidrolítica}

A atividade hidrolítica das células foi determinada pelo método de hidrólise, conforme metodologia modificada por Andrade et al. (2014). O substrato foi preparado pela emulsão de $10 \mathrm{~mL}$ de azeite de oliva e $90 \mathrm{~mL}$ de água destilada e goma arábica a $3 \%\left(\mathrm{~m} \mathrm{v}^{-1}\right)$. Em frascos Erlenmeyer ${ }^{\circledR}$ de $125 \mathrm{~mL}$ foram adicionados $5 \mathrm{~mL}$ de substrato, $4 \mathrm{~mL}$ de solução tampão fosfato de sódio $(0,1 \mathrm{M}, \mathrm{pH} 8,0)$ e $1 \mathrm{~g}$ de células (massa seca) ou 1,0 $\mathrm{ml}$ do caldo fermentado. Os frascos foram incubados a $37^{\circ} \mathrm{C}$ por 5 minutos, em banho termostatizado com agitação. Após o período de incubação, a reação foi paralisada pela adição de $10 \mathrm{~mL}$ de uma mistura de etanol e água

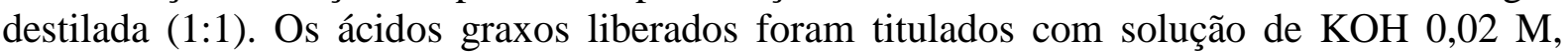
utilizando fenolftaleína como indicador. Os cálculos foram realizados pela Equação 1, sendo uma unidade de atividade definida como a quantidade de enzima que libera $1 \mu$ mol de ácido graxo por minuto de reação, nas condições do ensaio. As atividades são expressas em $\mu \mathrm{mol} \mathrm{g}{ }^{-1}$ $\min ^{-1}\left(\mathrm{U} \mathrm{g}^{-1}\right)$. 


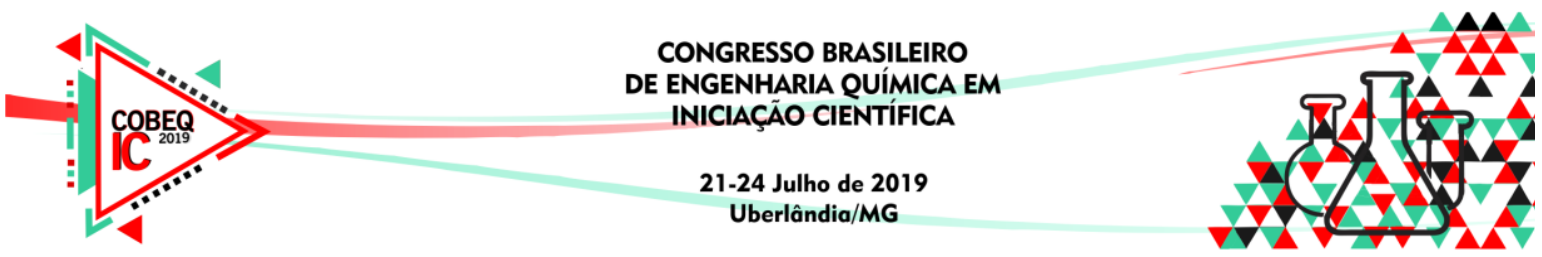

$A(U)=\frac{\left(V_{a}-V_{b}\right) * M_{K O H} * 10^{3}}{t * m_{\text {seca }}}$

em que $V_{a}$ representa o volume de titulante gasto na titulação da amostra $(\mathrm{mL}), V_{b}$ representa o volume de titulante gasto na titulação do branco $(\mathrm{mL}), M_{K O H}$ representa a molaridade do titulante utilizado $\left(\mathrm{mol} \mathrm{L}^{-1}\right), \mathrm{t}$ representa o tempo de reação $(\mathrm{mim})$ e $m_{\text {seca }}$ a quantidade de massa seca de biocatalisador utilizada durante a reação $(\mathrm{g})$ ou a quantidade do caldo fermentado utilizado durante a reação $(\mathrm{g})$.

\section{RESULTADOS E DISCUSSÃO}

\subsection{Produção das células íntegras}

A fim de avaliar a cinética de crescimento e a atividade hidrolítica das células íntegras de A. oryzae, bem como do filtrado obtido após a separação das células do meio fermentado, um cultivo inicial utilizando azeite de oliva como fonte de carbono e peptona de soja como fonte de nitrogênio em $\mathrm{pH}$ in natura $(6,5)$ foi realizado. O perfil cinético e as atividades hidrolíticas da biomassa e do filtrado estão ilustrados na Figura 1a-b.

Figura 1 - Perfil cinético de crescimento (a) e atividades hidrolíticas das células íntegras de A. oryzae e do filtrado obtido após a fermentação (b). Condições: pH 6,5; azeite de oliva; peptona de soja; $30^{\circ} \mathrm{C} ; 170 \mathrm{rpm}$.

(a)

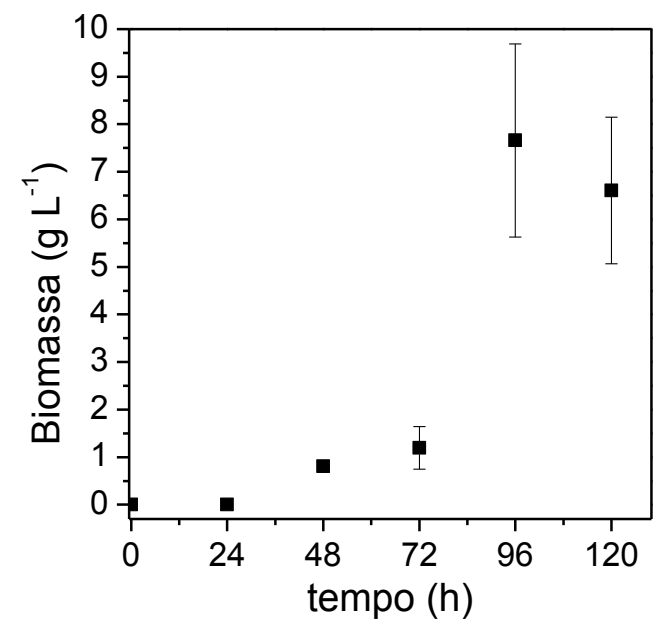

(b)

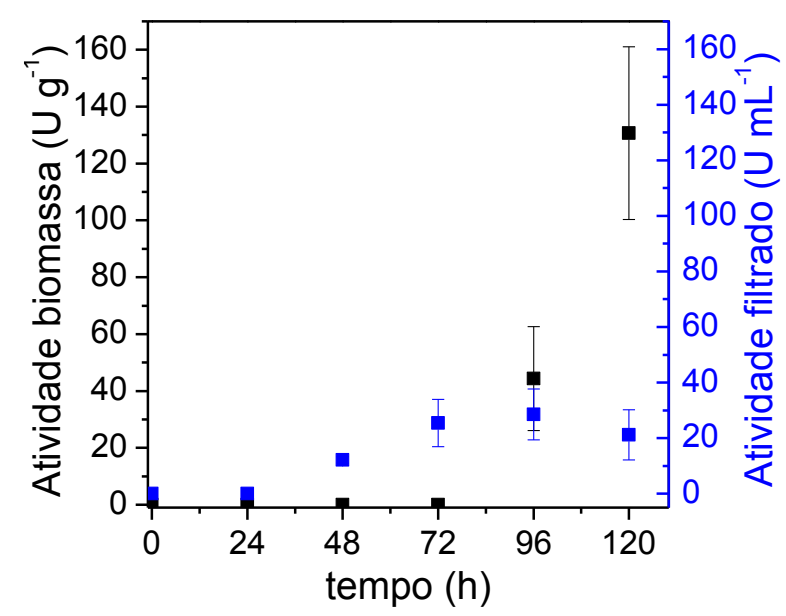

O perfil de crescimento (Fig. 1a) mostra um perfil típico de crescimento microbiano, em que não houve crescimento nas primeiras $24 \mathrm{~h}$ e uma fase lag de até $72 \mathrm{~h}$. A partir desse momento, o crescimento é exponencial e se estabiliza entre 96 e 120 h com valores máximos de 7,66 $\pm 2,03 \mathrm{~g} \mathrm{~L}^{-1}$. Durante esse período o $\mathrm{pH}$ foi monitorado e se manteve estável em 6,60 até $96 \mathrm{~h}$, sendo que em $120 \mathrm{~h}$ observou-se um decréscimo para 5,9. No mesmo período a atividade hidrolítica da biomassa e do filtrado também foi monitorada (Fig.1b). Os dados revelam que a maior atividade do filtrado foi cerca de 4 vezes menor em relação a da biomassa, indicando que a maior parte da lipase produzida ficou ligada ao micélio e não foi secretada para 


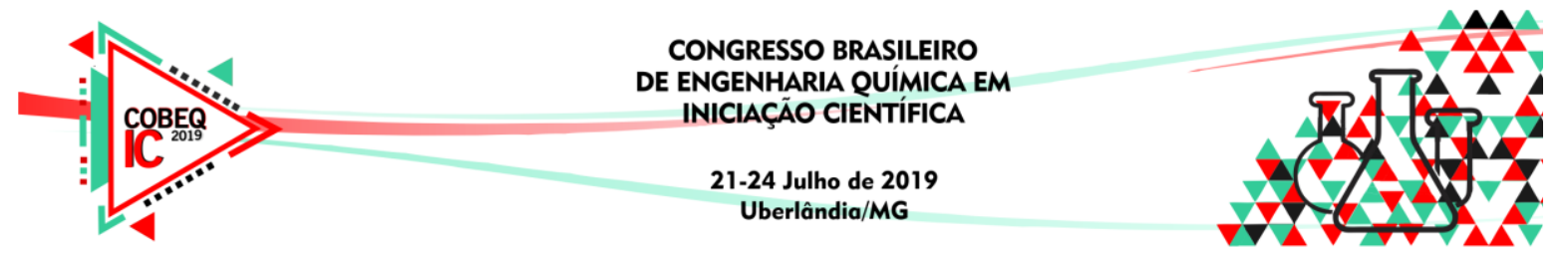

o meio. Até 72h não foi observado atividade na biomassa, sendo a lipase produzida somente a partir de 96h. O máximo valor de atividade da biomassa foi de 130,65 $\pm 30,65 \mathrm{U} \mathrm{g}-1 \mathrm{em} 120 \mathrm{~h}$.

\subsection{Influência dos parâmetros de cultivo na produção de células íntegras}

A fim de maximizar a produção de lipase ligada ao micélio, o meio de cultivo das células íntegras de $A$. oryzae foi avaliado sob diferentes valores de $\mathrm{pH}$, fontes de carbono e fontes de nitrogênio. Inicialmente avaliou-se a influência da fonte de carbono na produção de biomassa e de lipase ligada ao micélio sob cultivo em $\mathrm{pH}$ in natura $(6,5)$ e peptona de soja $\left(70 \mathrm{~g} \mathrm{~L}^{-1}\right)$ como fonte de nitrogênio. Os resultados obtidos estão ilustrados na Figura 2a-b.

Figura 2 - Perfil cinético de crescimento (a) e atividades hidrolíticas das células íntegras de $A$. oryzae e do filtrado obtido após a fermentação (b). Condições: azeite de oliva; peptona de soja; $30^{\circ} \mathrm{C} ; 170 \mathrm{rpm}$.

(a)

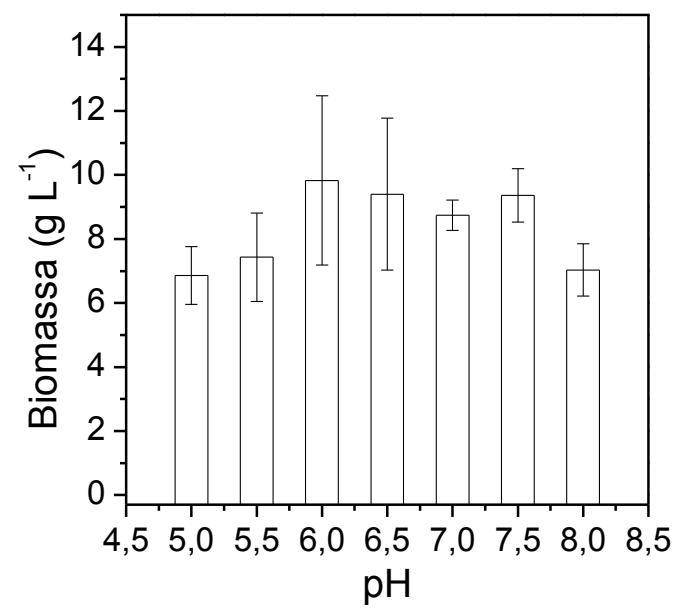

(b)

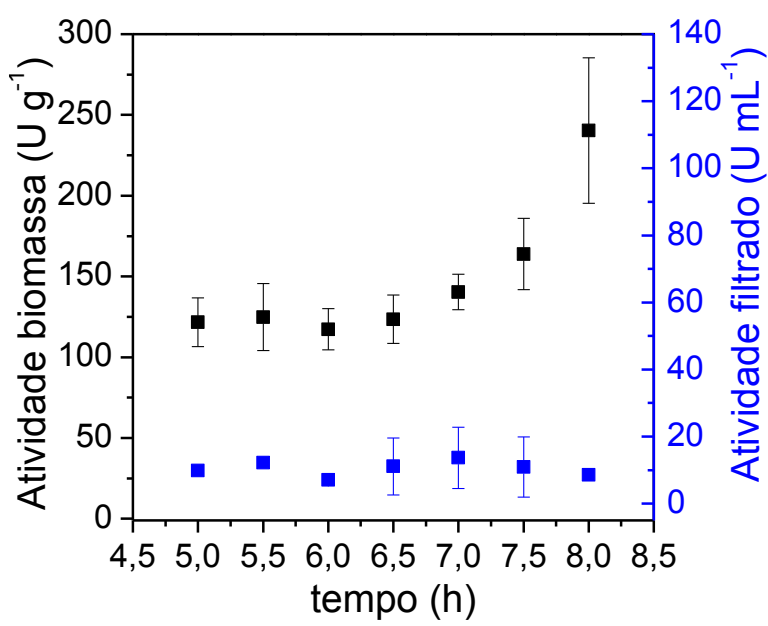

Verificou-se na Fig. 2a que a mudança de $\mathrm{pH}$ do meio não provocou uma variação expressiva na produção da biomassa que ficou entre $6,85 \pm 0,90$ e 9,83 $\pm 2,65 \mathrm{~g} \mathrm{~L}^{-1}$. Comportamento semelhante ocorreu para a atividade do filtrado que manteve-se baixa com valores médios de 10,48 $\pm 1,29 \mathrm{U} \mathrm{g}^{-1}$. Por outro lado a atividade da biomassa aumentou com o aumento do $\mathrm{pH}$ do meio, atingindo o valor máximo de 240,37 $\pm 45,09 \mathrm{U} \mathrm{g}^{-1} \mathrm{em} \mathrm{pH} \mathrm{8,0.}$

Definido pH 8,0 como o ideal, testou-se diferentes óleos refinados como fontes de carbono e fixou-se peptona de soja como fonte de nitrogênio. Os resultados obtidos estão ilustrados na Figura 3a-b.

Figura 3 - Perfil cinético de crescimento (a) e atividades hidrolíticas das células íntegras de A. oryzae e do filtrado obtido após a fermentação (b). Condições: pH 8,0; peptona de soja; $30^{\circ} \mathrm{C} ; 170 \mathrm{rpm}$. 


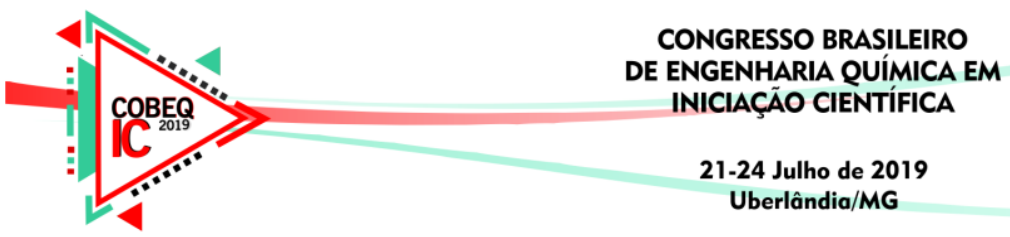

(a)

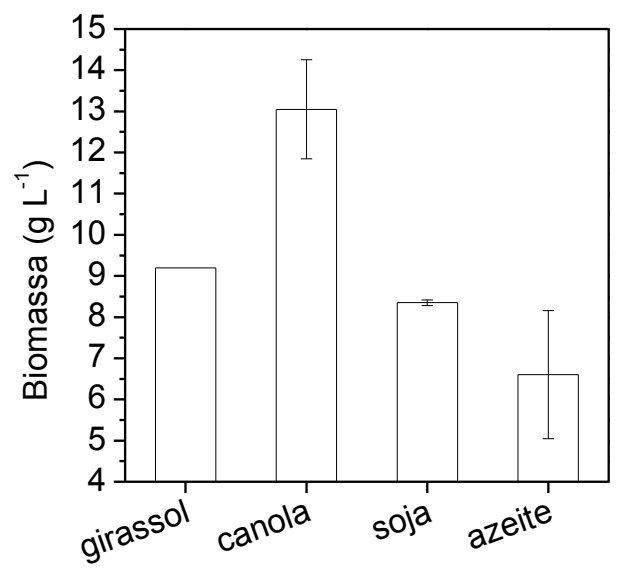

(b)

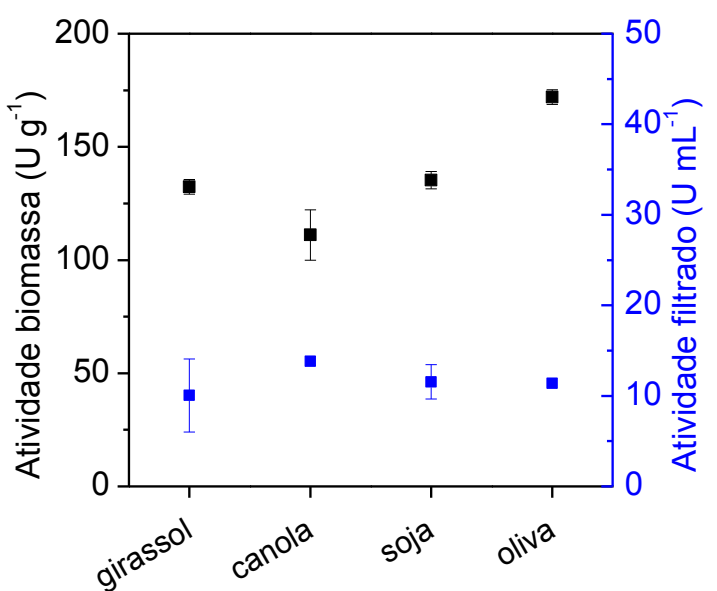

A Fig.3a mostra que o óleo de canola favoreceu a produção de biomassa $(13,05 \pm 1,20$ $\left.\mathrm{g} \mathrm{L}^{-1}\right)$, porém não favoreceu a produção de lipase ligada ao micélio, visto que a maior atividade da biomassa $\left(171,97 \pm 3,2 \mathrm{U} \mathrm{g}^{-1}\right)$ foi obtido com o emprego de óleo de oliva no cultivo. A atividade do filtrado manteve-se baixa, indicando que a mudança na fonte de carbono não influenciou a retenção da lipase produzida.

O último teste foi avaliar a fonte de nitrogênio, fixando-se óleo de oliva como fonte de carbono e pH 8,0. Os resultados obtidos estão ilustrados na Figura 4a-b.

Figura 4 - Perfil cinético de crescimento (a) e atividades hidrolíticas das células íntegras de A. oryzae e do filtrado obtido após a fermentação (b). Condições: pH 8,0; óleo de oliva; $30^{\circ} \mathrm{C} ; 170 \mathrm{rpm}$.

(a)

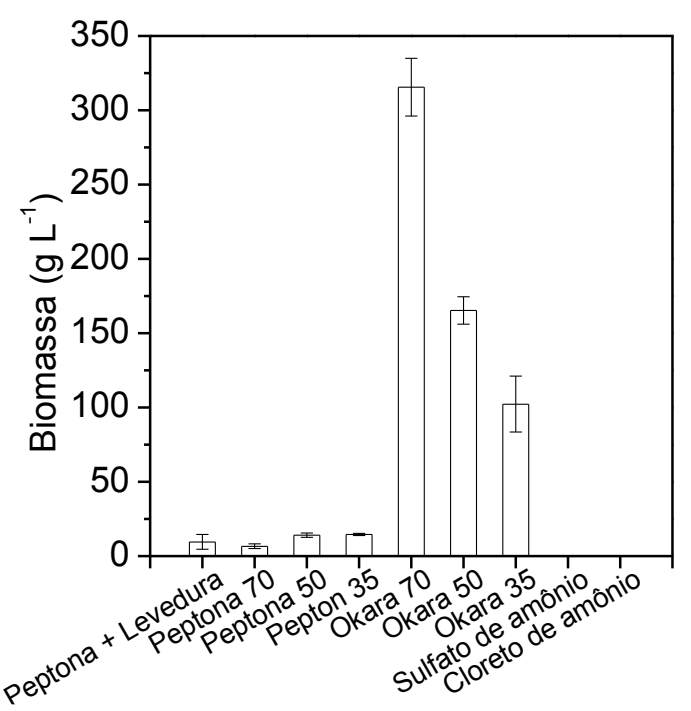

(b)

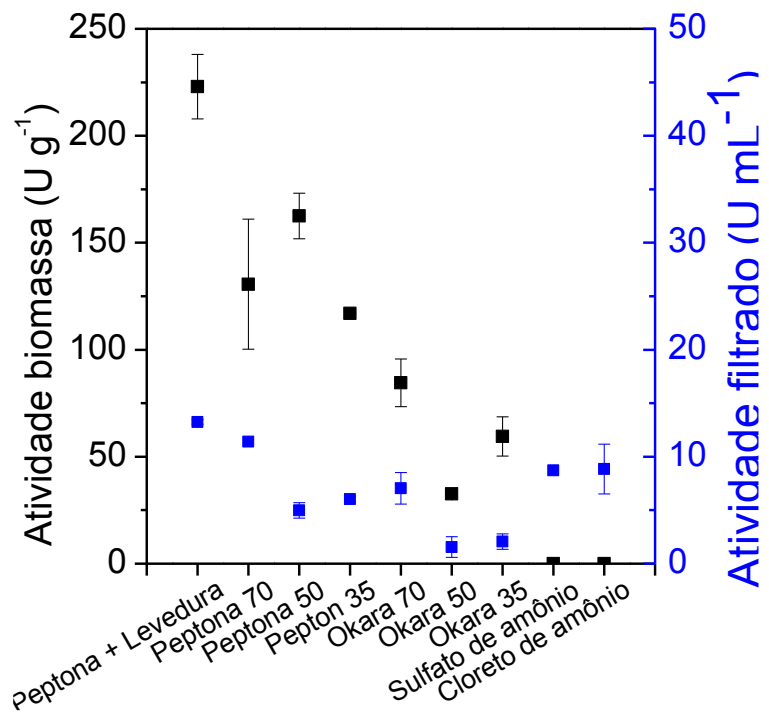




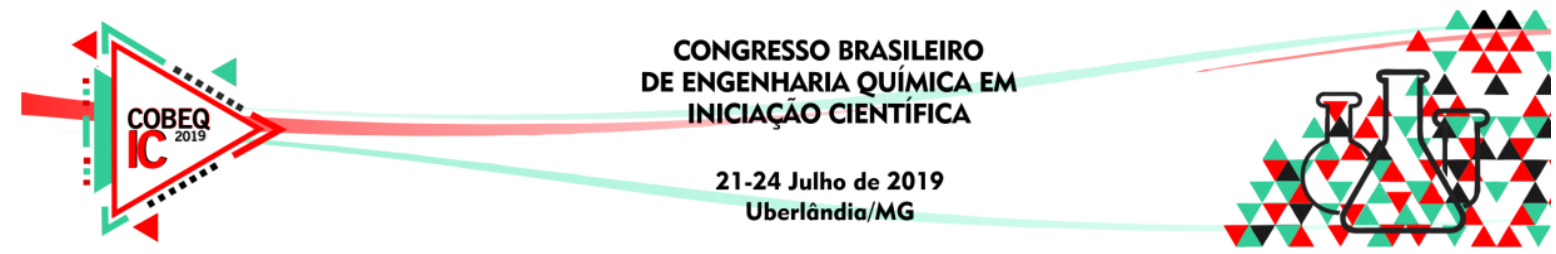

A Fig. 4 mostra que o okara favorece o crescimento celular, porém a máxima atividade de biomassa $\left(223,02 \pm 15,07 \mathrm{U} \mathrm{g}^{-1}\right)$ foi atingida utilizando a mistura 1:1 de peptona de soja e extrato de levedura na concentração de $70 \mathrm{~g} \mathrm{~L}^{-1}$. A presença dos sais $\left(\mathrm{NH}_{4}\right)_{2} \mathrm{SO}_{4}$ e $\mathrm{NH}_{4} \mathrm{Cl}$ não promoveram crescimento da biomassa no meio de cultivo. Observa-se ainda que a fonte de nitrogênio também não afetou a retenção de lipase na biomassa, uma vez que as atividades de filtrado permaneceram baixas.

\section{CONCLUSÃO}

Os dados obtidos neste trabalho sugerem que a produção de lipase ligada ao micélio pode ser otimizada variando apenas as condições de cultivo das células íntegras. Ao empregar azeite de oliva como fonte de carbono, a mistura de peptona de soja e extrato de levedura como fonte de nitrogênio e o ajuste do $\mathrm{pH}$ do meio para 8,0, obteve-se a máxima atividade hidrolítica da biomassa, o que evidencia que essas são as condições que favorecem a retenção da lipase ao micélio.

\section{AGRADECIMENTOS}

Os autores agradecem o suporte financeiro da CAPES Código Financeiro 001 e FAPEMIG (APQ-01391-18).

\section{REFERÊNCIAS}

ANDRADE, G. S. S.; CARVALHO, A. K. F.; ROMERO, C. M., OLIVEIRA, P. C.; DE CASTRO, H. F. Mucor circinelloides whole-cells as a biocatalyst for the production of ethyl esters based on babassu oil. Bioprocess Biosyst. Eng. v.37, n. 12, p. 25392548 , 2014.

ANDRADE, G. S. S.; FREITAS, L.; OLIVEIRA, P. C.; DE CASTRO, H.F. Screening, immobilization and utilization of whole cell biocatalysts to mediate the ethanolysis of babassu oil. J Mol Catal B Enzym. v. 84, p. 183-188, 2012.

COLLA, L. M.; PRIMAZ, A. L.; BENEDETTI, S.; LOSS, R. A.; DE LIMA, M.; REINEHR, C. O.; BERTOLIN, T. E.; COSTA, J. A. V. Surface response methodology for the optimization of lipase production under submerged fermentation by filamentous fungi. Brazilian J Microbiol. v. 47, n. 2, p. 461-467, 2016.

CORTEZ, D. V.; DE CASTRO, H. F.; ANDRADE, G. S.S. Potencial catalítico de lipases ligadas ao micélio de fungos filamentosos em processos de biotransformação. Quím. Nova. v. 40, n.1, p. 85-96, 2016.

IFTIKHAR, T. MUBASHIR, N.; AFZAL, M.; HAQ, I.; RAJOKA, M. I. Maximization of intracellular lipase production in a lipase-overproducing mutant derivative of Rhizopus oligosporus DGM 31: a kinetic study. Food Technol. Biotechnol. v. 46, n. 4, p. 402-412, 2008 . 